\title{
The Effect of Selected Anions on Dipalmitoylphosphatidylcholine Phase Transitions
}

Adriana Przyczyna ${ }^{\mathrm{a}, *}$, Bożenna Różycka-Roszk ${ }^{\mathrm{b}}$ and Marek Langner ${ }^{\mathrm{c}, \mathrm{d}}$

a Department of Physics and Biophysics, Agricultural Academy, ul. Norwida 25, 50-375 Wrocław, Poland. Fax: 48713205172. E-mail: mucha@ozi.ar.wroc.pl

b Department of Physics and Biophysics, Agricultural Academy, ul. Norwida 25, 50-375 Wrocław, Poland

c Institute of Physics, Wrocław University of Technology, Wyb. Wyspiañskiego 27, 50-370 Wrocław, Poland

d Academic Center for the Biotechnology of Lipid Aggregates, ul. Przybyszewskiego 63/67, 51-148, Wrocław, Poland

* Author for corresponding and reprint requests

Z. Naturforsch. 57 c, 712-716 (2002); received March 7/May 6, 2002

Phase Transition, Lipid Bilayer, Calorimetry

The effect of three anions, $\mathrm{Cl}^{-}, \mathrm{Br}^{-}$and $\mathrm{I}^{-}$, on the phase transitions of dipalmitoylphosphatidylcholine (DPPC) was measured. Main phase transition was modestly affected by these anions in the salt concentration range $0.2 \mathrm{M}$. For $\mathrm{Cl}^{-}$and $\mathrm{Br}^{-}$the temperature of main phase transition was lower (by about $0.5^{\circ} \mathrm{C}$ ), its half-width modestly larger and enthalpy practically unchanged, all three parameters were altered to a much larger degree. Main phase transition temperature was $1.5^{\circ} \mathrm{C}$ lower and the peak half-width significantly smaller. These changes were not accompanied by any alteration in main phase transition enthalpy. Iodide shifted the pretransition temperature toward lower values and increased its half-width to such an extent that at concentrations above $100 \mathrm{~mm}$ it was practically undetectable. Besides cations, the presence of anions also has a distinct effect on lipid bilayer interface properties.

\section{Introduction}

The lipid bilayer, an aqueous solution interface, determines all membrane surface-associated events and constitutes a complex multicomponent system that depends on both lipid bilayer and aqueous phase composition (Cevc, 1990; Langner and Kubica, 1999). The effect of various ions dissolved in the aqueous phase on the lipid bilayer has been extensively studied in the past (Cevc, 1990; Koynova et al., 1997; Sturtevant, 1998). However, research has been focused almost exclusively on cations since they are known to participate in many cellular events, $\mathrm{Ca}^{2+}$ being the most spectacular example (Berridge, 1993; Goldberg et al., 1994; Huster et al., 2000).

However, there are limited literature data regarding the effect of anions on lipid bilayer state despite the fact that iodide, for example has been widely used as a quencher of tryptophan fluorescence (Eftnik and Ghiron, 1981; Lakowicz, 1988). When the quenching technique is applied, an assumption that the quenching compound (iodide) does not interfere in protein-membrane interaction is mandatory, especially if the applied concentrations are high (up to $1 \mathrm{M}$ ). It has been shown that iodide ions bind to the lipid bilayer surface and are even capable of penetrating its hydrophobic core through structural defects [at main phase transition (Langner and Hui, 1991)]. There are also limited data that exhibit anions as potent cofactors in metabolic processes, for instance the effect of iodide ions in the aqueous phase on the efficiency of lipid hydrolysis induced by oligonucleotides (Moog et al., 2000). The relative neutrality of anions observed in various studies results from the fact that naturally occurring lipids are predominantly neutral or negatively charged, causing surface anion concentrations to be lower then that in the bulk and masking their potential effects (Cevc, 1990). The influence of anions on lipids can be more subtle (however), i.e. they can reorganize the layer of bound water at the membrane interface and consequently affect overall membrane state and/or topology. Altered water structure can also affect a variety of membraneassociated processes, such as macromolecule in- 
teraction with lipid surfaces (Gawrish et al., 1992; Marrink et al., 1996) and membrane fusion (Chizmadzhev et al., 2000; Marchi-Artzner et al., 2001), or interfere with enzymatic reactions that occur at the membrane interface. The role of anions becomes even more relevant when positively charged amphiphiles are employed as membrane components (Anwer et al., 2000; Byk and Scherman, 2000) or the interactions of amphiphilic salts with membranes in considered. The influence of chloride, bromide and iodide as counterion of amphphilic compounds was shown on the calcium desorption from liposomes (Różycka-Roszak et al., 2001), the efficiency of the surfactant to destabilize model membranes (Sarapuk et al., 1999), as well as thermotrpic phase behaviour of phosphatidylcholine (Różycka-Roszak and Pruchnik, 2000), and phosphatidylcholine/cholesterol bilayers (Różycka-Roszak and Pruchnik, 2000).

In this paper, the effect of three anions (chloride, iodide and bromide) on the thermotropic properties of dipalmitoylphosphatidylcholine are presented. DPPC is known to have two distinct phase transitions, i.e. pretransition (associated with changes in lipid headgroup organization) and main phase transition (reflecting changes in hydrocarbon chain organization) (Koynova and Caffrey, 1998; Seddon and Tampler, 1995). Salts were selected as to keep their cations constant $\left(\mathrm{Na}^{+}\right)$ whereas the anion varied. The presence of salt either in or below the physiological concentration range altered DPPC thermograms, with iodide being the most potent.

\section{Materials and Methods}

\section{Chemicals}

1,2-dipalmitoyl-sn-glycero-3-phosphocholine (DPPC) was purchased from Avanti Polar Lipids (Birmingham, Alabama, USA). Sodium chloride $(\mathrm{NaCl})$, bromide $(\mathrm{NaBr})$, iodide $(\mathrm{NaI})$ and all other chemicals were obtained from Fluka Chemie AG (Switzerland).

\section{Sample preparation and calorimetric measurements}

Differential scanning calorimetry (DSC) was carried out using multilamellar lipid vesicles (MLVs). Samples were prepared as follows; DPPC dissolved in chloroform was evaporated and kept under vac- uum for two hours in order to remove all traces of chloroform. The dry lipid film was then hydrated with a water solution of $\mathrm{NaCl}, \mathrm{NaBr}$ or $\mathrm{NaI}$ at an appropriate concentration. MLVs were formed by agitation on a vortex mixer. The vesicle suspension was then heated to $60{ }^{\circ} \mathrm{C}$ for $15 \mathrm{~min}$ and finally left to $4{ }^{\circ} \mathrm{C}$ for two days. Such a lipid suspension was loaded into the sample cell of a DSC microcalorimeter (Mettler Toledo Thermal Analysis System D. S. C. 821). All thermograms were taken at a scan rate of $2{ }^{\circ} \mathrm{C} / \mathrm{min}$. The lipid concentration of all samples was the same, namely $25 \mathrm{mg} / \mathrm{ml}$.

All measurements were repeated at least three times for independently prepared samples, so as to ensure reproducibility. Selected samples were measured several times (4), making the calculation of deviation from average values possible. The reproducibility of sample preparations was evaluated with the help of DPPC thermograms in water. Sample series were discarded when the DPPC thermogram deviated from the expected one.

\section{Results and Discussion}

Differential Scanning Calorimetry was used to study the effect of three selected anions (chloride $\mathrm{Cl}^{-}$, iodide $\mathrm{I}^{-}$and bromide $\mathrm{Br}^{-}$) on DPPC lipid bilayer phase transitions in the continuous presence of the $\mathrm{Na}^{+}$cation. Their effect on pre- and main phase transition temperatures, and transition pick-width and enthalpies was determined. The dependence of main phase transition temperature on salt concentration is summarized in Figure 1A: the temperature of main phase transition is lower in all cases. This shows that the presence of any salt alters lipid bilayer hydrocarbon chain organization. The effect is most evident when $\mathrm{I}^{-}$is present in the aqueous phase. When iodide concentration grows to $50 \mathrm{~mm}$, main phase transition temperature decreases from $41.4{ }^{\circ} \mathrm{C}$ down to $40.9^{\circ} \mathrm{C}\left( \pm 0.05^{\circ} \mathrm{C}\right)$, and remains constant at higher concentrations. The decrease in main phase transition temperature was much smaller for the two remaining salts, i.e. from $41.4^{\circ} \mathrm{C}$ to $41.1^{\circ} \mathrm{C}$. With rising salt concentration the peak half-width of main phase transition broadened for $\mathrm{NaCl}$ and $\mathrm{NaBr}$, whereas it sharpened for NaI. Such behaviour indicates increased cooperativity in the hydrocarbon chain region for this salt (Fig. 1B). The presence of all salts (up to $100 \mathrm{~mm}$ ) altered main 


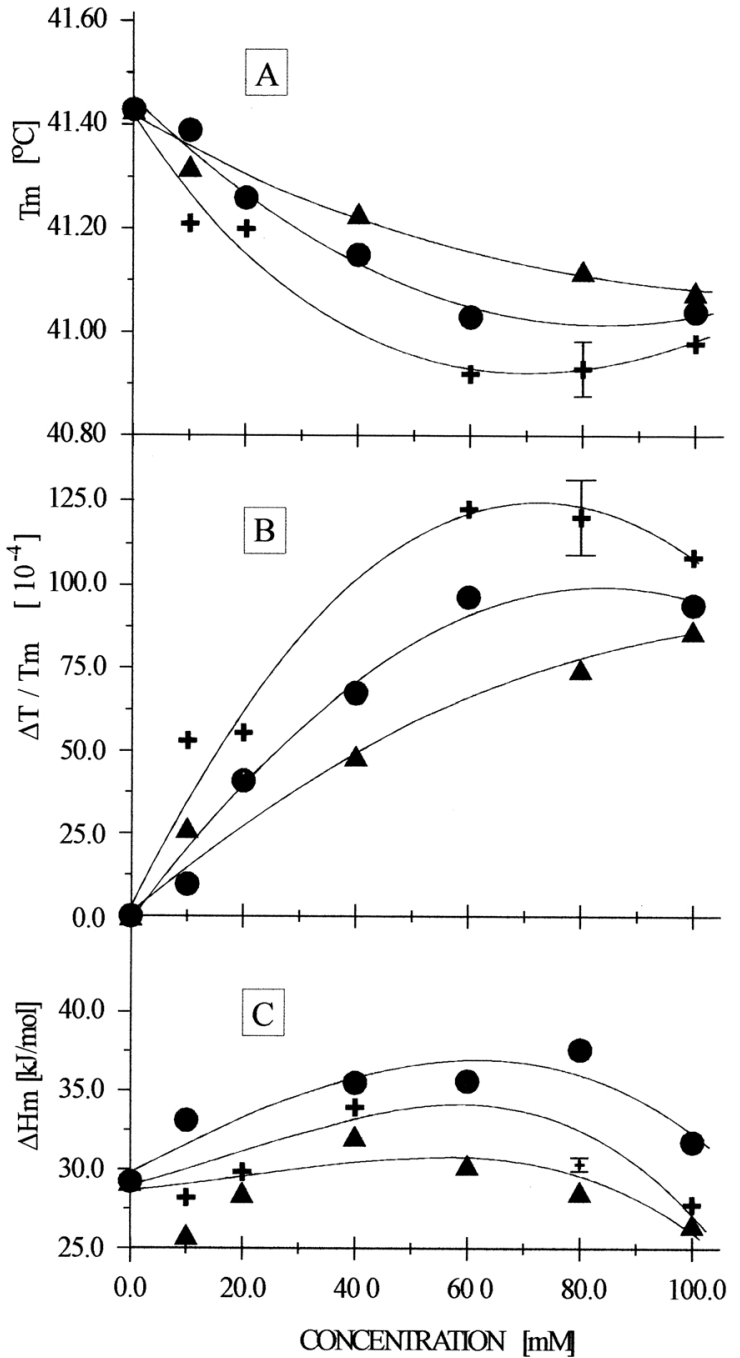

Fig. 1. The dependences of main phase transition characteristics on the concentration of $\mathrm{NaCl}$ (triangles), $\mathrm{NaBr}$ (circles) and $\mathrm{NaI}$ (cross).

( Tm - the temperature of main phase transition; $\Delta \mathrm{T} /$ $\mathrm{Tm}$ - the relative half-width of the main phase transition peak; $\Delta \mathrm{Hm}$ - the enthalpy of main phase transition.)

phase transition enthalpy in a non-monotonous meaner (Fig. 1C). Enthalpy increases for rising concentrations up to $100 \mathrm{~mm}$, and drops down for higher ones.

A more prominent effect was observed upon pretransition analysis. For all salts pretransition temperature was significantly shifted toward lower ones (Fig. 2A). Again, the effect of $\mathrm{I}^{-}$was the largest - pretransition temperature fell by $3.5^{\circ} \mathrm{C}$

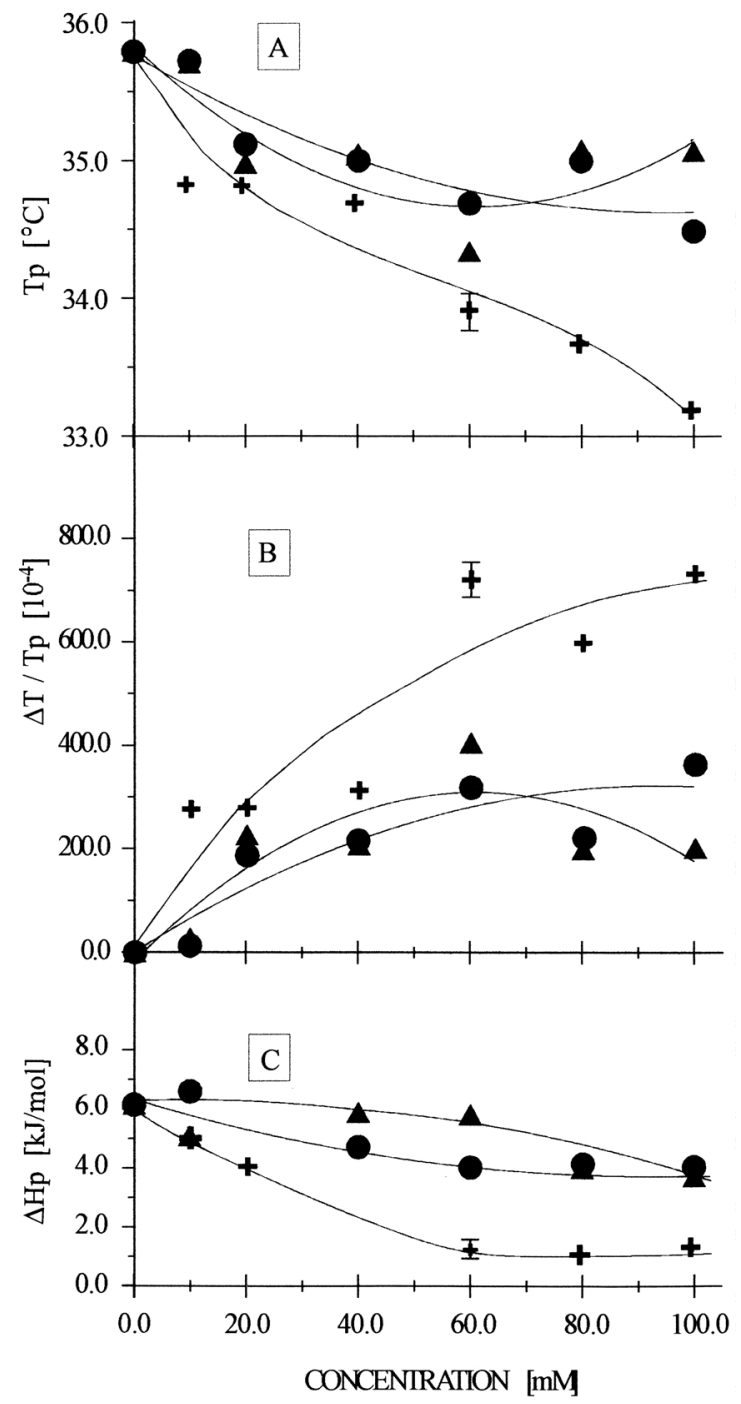

Fig. 2. The dependences of pretransition characteristics on the concentration of $\mathrm{NaCl}$ (triangles), $\mathrm{NaBr}$ (circles) and $\mathrm{NaI}$ (cross).

( Tp - the temperature of pretransition; $\Delta \mathrm{T} / \mathrm{Tp}-$ the relative half-width of pretransition peak; $\Delta \mathrm{Hp}$ - the enthalpy of pretransition.)

(from $36.5^{\circ} \mathrm{C}$ to $33^{\circ} \mathrm{C}$ ). The shift was much smaller for the two other salts (by about $1.5^{\circ} \mathrm{C}$ ). Determining pretransition half-width is difficult as its peak becomes smeared. Crude estimation reveals half-width to have increased twice as much for $100 \mathrm{~mm}$ of $\mathrm{NaI}$ than for $100 \mathrm{~mm}$ the two remaining salts (Fig. 2B). When pretransition enthalpy was calculated, there were no measurable changes in the entire $\mathrm{NaCl}$ and $\mathrm{NaBr}$ concen- 
tration range, whereas it dropped to zero for $\mathrm{NaI}$ concentrations above $100 \mathrm{~mm}$. This indicates significant alteration of the interfacial region (Fig. 2C).

Presented data confirm previous observations presented in literature that the presence of salt alters lipid bilayer phase behavior (Cevc, 1990; Cevc, 1991; Koynova et al., 1997). Most studies up to date were focused on the effect of cations, in light of their physiological relevancy (Koynova and Caffrey, 1998), and with major emphasis on calcium (Goldberg et al., 1994; Sturtevant, 1998) due to its role in second messenger cascades (Berridge, 1993). Only recently has the ability of ions to alter water structure been included in studies of membrane associated phenomena (Collins, 1997; Collins, 1995; Koynova et al., 1997). In this respect, the ability of anions to affect lipid bilayer state follows the Hofmeister series $\mathrm{I}^{-}, \mathrm{Br}^{-}, \mathrm{Cl}^{-}$, which reflects charge density and the ratio of ion-water to water-water interaction strengths. The ability of such ions to disturb the water layer that is adjacent to the membrane is likely to be an important factor (Cevc, 1991; Gawrish et al., 1992; Marrink et al., 1996). Since the biological membrane sur-

Anwer K., Meaney C., Kao G., Hussain N., Shelvin R. Earls R. M., Leonard P., Quezada A., Rolland A. P. and Sullivan S. M. (2000), Cationic lipid-based delivery system for systemic cancer gene therapy. Cancer Gene Ther. 7, 1156-1164.

Berridge M. J. (1993), Inositol triphosphate and calcium signaling. Nature 361, 315-325.

Byk G. and Scherman D. (2000), Genetic chemistry: tool for gene therapy coming from unexpected directions. Drug Develop. Res. 50, 566-572.

Cevc G. (1991), Hydration force and the interfacial structure of the polar surface. J. Chem. Soc. Faraday Trans. 87, 2733-2739.

Cevc G. (1990), Membrane electrostatics. Biochim. Biophys. Acta 1031-3, 311-382.

Cevc G. (1990), The molecular interaction between monovalent ions and polar surfaces, such as lipid bilayer membranes. Chem. Phys. Lett. 170, 283-288.

Cevc G. (1991), Polymorphism of the bilayer membranes in the ordered phase and the molecular origin of the lipid pretransition and rippled lamellae. Biochim. Biophys. Acta 1062, 59-69.

Chizmadzhev Y. A., Kuzmin P. I., Kurenko D. A., Zimmerberg J. and Cohen F. S. (2000), Dynamics of fusion pores connecting membranes of different tensions. Biophys. J. 78, 2241-2256. face is neutral or negatively charged, the presence of a small amount of anions there can have only limited effect in terms of electrostatic interactions. However, if surface potential was positive, it would be expected to become substantial (Cevc, 1990). Such a situation is anticipated when cationic liposome-DNA complexes are studied. Our own observations show that the presence of iodide in the millimolar range is capable of inducing the nucleotide dissociation from the positively charged membrane surface.

In addition, the presented data are relevant for methodological reasons, since iodide is frequently applied as a fluorescence quencher of tryptophans. Iodide concentrations are then significantly higher than those used in this paper, making iodide interference in protein-membrane interactions feasible.

\section{Acknowledgments}

This work was possible thanks to the financial support of the Institute of Physics, Wrocław University of Technology, and the Biocenter for Biomonitoring, Biotechnology and the Protection of the Lower Silesia Ecosystem.

Collins K. D. (1997), Charge density-dependent strength of hydration and biological structure. Biophys. J. 72, $65-76$.

Collins K. D. (1995), Sticky ions in biological systems. Proc. Natl. Acad. Sci. USA 92, 5553-5557.

Eftnik M. R. and Ghiron C. A. (1981), Flourescence quenching studies with proteins. Anal. Biochem. 114, $199-227$.

Gawrish K., Ruston D., Zimmerberg J., Persegian V. A., Rand R. P. and Fuller N. (1992), Membrane dipole potentials, hydration forces, and the ordering of water at membrane surface. Biophys. J. 61, 1213-1223.

Goldberg H., Maxwell P., Hack N. and Skorecki K. (1994), Reduced Phospholipase $\mathrm{A}_{2}$ activity is not accompanied by reduced arachidonic acid release. Biochem. Biophys. Res. Commun. 198, 220-227.

Huster D., Arnold K. and Gawrisch K. (2000), Strength of $\mathrm{Ca}^{2+}$ binding to retinal lipid membrane: consequences for lipid organization. Biophys. J. 78, $3011-$ 3018 .

Koynova R., Brankov J. and Tenchov B. (1997), Modulation of lipid phase behavior by kosmotropic and chaotropic solutes. Eur. Biophys. J. 25, 261-274.

Koynova R. and Caffrey M. (1998), Phases and phase transitions of the phosphatidylcholines. Biochim. Biophys. Acta 1376, $91-145$. 
Lakowicz J. R. (1988), Principles of frequency-domain fluorescence spectroscopy and applications to cell membranes. In: Subcellular Biochemistry, Vol. 13 (H. J. Hilderson, ed.). Plenum Press, New York, pp. 89-126.

Langner M. and Hui S. W. (1991), Iodide penetration into lipid bilayers as a probe of membrane lipid organization. Chem. Phys. Lipids 60, 127-132.

Langner M. and Kubica K. (1999), The electrostatics of lipid surfaces. Chem. Phys. Lipids 101, 3-35.

Marchi-Artzner V., Gulik-Krzywicki T., GuedeauBoudeville M. A., Gosse C., Sanderson J. M., Dedieu J. C. and Lehn J. M. (2001), Selective adhesion, lipid exchange and membrane-fusion processes between vesicles of various sizes bearing complementary molecular recognition groups. Europ. J. Chem. Phys. Chem. 2, 367-376.

Marrink S. J., Tieleman D. P., v. Buuren A. R. and Berendsen H. J. C. (1996), Membrane and water: an interesting relationship. Faraday Discuss. 103, 191-201.

Moog R., Brandl M., Schubert R., Unger C. and Massing U. (2000), Effect of nucleotide analogues and oligonucleotides on hydrolysis of liposomal phospholipids. Int. J. Pharmaceut. 206, 43-53.
Różycka-Roszak B. and Pruchnik H. (2000), Influence of dodecyltrimethylammonium halides on thermotropic phase behaviour of phosphatidylcholine/cholesterol bilayers. Z. Naturforsch. 55c, 753-757.

Różycka-Roszak B. and Pruchnik H. (2000), Effect of counterions of dodecyltrimethylammonium halides on thermotropic phase behaviour of phosphatidylcholine bilayers. Z. Naturforsch. 55c, 240-244.

Różycka-Roszak B., Żyłka R., Kral T. and Przyczyna A. (2001), Counterion effect on the interaction of amphiphilic quaternary ammonium salts with model membranes. Z. Naturforsch. 56c, 407-412.

Sarapuk J., Kleszczyńska H., Pernak J., Kalewska J. and Różycka-Roszak B. (1999), Influence of counterions on the interaction of pyridinium salts with model membranes. Z. Naturforsch. 54c, 952-955.

Seddon J. M. and Tampler R. H. (1995), Polymorphism of lipid-water systems. In: Handbook of biological physics, Vol. 1 (R. Lipowsky and E. Sackmann, ed.). Elsevier Science B. V., North Holland.

Sturtevant J. M. (1998), The effect of sodium chloride and calcium chloride on the main phase transition of dimyristoylphosphatidyl-choline. Chem. Phys. Lipids 95, 163-168. 